\title{
Avian Mycobacteriosis: Still Existing Threat to Humans
}

\author{
Michal Slany, ${ }^{1}$ Vit Ulmann, ${ }^{2}$ and Iva Slana ${ }^{1}$ \\ ${ }^{1}$ Veterinary Research Institute, Hudcova 70, 62100 Brno, Czech Republic \\ ${ }^{2}$ Institute of Public Health in Ostrava, Partyzanske Namesti 7, 70200 Ostrava, Czech Republic \\ Correspondence should be addressed to Michal Slany; slany@vri.cz
}

Received 17 February 2016; Revised 31 May 2016; Accepted 19 June 2016

Academic Editor: Hesham H. Ali

Copyright (C) 2016 Michal Slany et al. This is an open access article distributed under the Creative Commons Attribution License, which permits unrestricted use, distribution, and reproduction in any medium, provided the original work is properly cited.

\begin{abstract}
The nontuberculous mycobacteria are typically environmental organisms residing in soil and water. These microorganisms can cause a wide range of clinical diseases; pulmonary disease is most frequent, followed by lymphadenitis in children, skin and soft tissue disease, and rare extra pulmonary or disseminated infections. Mycobacterium avium complex is the second most common cause of pulmonary mycobacterioses after $M$. tuberculosis. This review covers the clinical and laboratory diagnosis of infection caused by the members of this complex and particularities for the treatment of different disease types and patient populations.
\end{abstract}

\section{Introduction}

Mycobacteria are acid-fast Gram-positive bacilli characterized as intracellular parasites. As of today, 169 mycobacterial species and 13 subspecies have been identified [1]. This large group includes obligate pathogenic mycobacteria causing tuberculosis (members of the Mycobacterium tuberculosis complex; MTC) and leprosy (M. leprae), as well as nontuberculous mycobacteria (NTM), occurring widely in the environment [2].

The Czech Republic has been certified to be free from bovine tuberculosis since 2004 [3]. It should be noted that tuberculous lesions have still been found in the lymph nodes and sporadically in the parenchymal organs of livestock (mainly cattle and pigs). When mycobacterial isolates from these tuberculous lesions were subjected to analysis, it was found that more than $95 \%$ were members of the Mycobacterium avium complex (MAC, [4]).

MAC are isolated increasingly in immunocompetent individuals [5]. Possible explanations include an increase in the number of individuals with lung damage making them more susceptible to mycobacterial infection, environmental exposure, or improved laboratory diagnostics.

An extensive analysis of the current literature has shown that members of the MAC are widely spread. In particular, two mycobacterial species belonging to the MAC (M. avium subsp. hominissuis and $M$. intracellulare) can be successfully propagated in the environment in high concentrations under certain conditions [6]. It should be, however, noted that even other nontuberculous mycobacteria can be potentially pathogenic (PPM) for humans and animals [4].

The natural reservoirs of these primarily nonpathogenic mycobacteria are aquatic and terrestrial environments [2]. Most of the PPM are able to produce biofilm, which is probably the main factor influencing their long-term survival in the environment and the emergence of possible sources of infection for humans and animals [7].

Infections caused by PPM are on the increase because of changes in lifestyle, environment, and other factors which affect the susceptibility of humans to disease. Infection with PPM is mainly manifested in functionally predisposed and immunocompromised individuals [8]. Most often it is a secondary immunodeficiency due to HIV infection or immunosuppressive treatment after transplantation or other systemic diseases [9]. The host is usually infected via inhalation of contaminated aerosols or via contact through subcutaneous skin abrasions [8]. PPM virulence is lower compared to M. tuberculosis [10], but in some cases, infection may have an aggressive course with systemic dissemination [11]. Interhuman transmission of PPM has not been demonstrated yet [6].

The aim of this review article is to explain the MAC taxonomy and summarize the occurrence of infections caused by MAC members in humans and animals. 
TABLE 1: M. tuberculosis and M. avium complex taxonomy.

\begin{tabular}{|c|c|}
\hline Member & Etiology \\
\hline \multicolumn{2}{|c|}{ M. tuberculosis complex } \\
\hline M. tuberculosis & $\begin{array}{l}\text { Human tuberculosis, occasionally } \\
\text { in animals in close contact with } \\
\text { infected patients }\end{array}$ \\
\hline M. bovis & $\begin{array}{l}\text { Tuberculosis in bovines and other } \\
\text { animals; humans are mainly } \\
\text { infected by drinking raw milk }\end{array}$ \\
\hline M. bovis BCG & The vaccine strain \\
\hline M. caprae & $\begin{array}{l}\text { Tuberculosis in bovines and other } \\
\text { animals; humans are infected } \\
\text { through the same pathways as for } \\
\text { M. bovis }\end{array}$ \\
\hline M. microti & $\begin{array}{l}\text { Tuberculosis in rodents, rarely other } \\
\text { animals and humans }\end{array}$ \\
\hline M. canettii & $\begin{array}{l}\text { Human infection, not detected in } \\
\text { animals }\end{array}$ \\
\hline M. africanum & $\begin{array}{l}\text { Human tuberculosis, rarely in } \\
\text { animals }\end{array}$ \\
\hline M. pinnipedii & $\begin{array}{l}\text { Tuberculosis in pinnipeds; animals } \\
\text { bred in captivity are the main } \\
\text { source of infection for caregivers }\end{array}$ \\
\hline
\end{tabular}

M. avium complex

M. avium subsp. avium

(serotypes 1-3)

M. avium subsp.

hominissuis (serotypes

4-6, 8-11, and 21)

M. intracellulare

(serotypes 7, 12-20, and Human infections

22-28)

M. colombiense

Human infections

M. chimaera

Human and animal infections

M. arosiense

Human infection

M. marseillense

Human infection

M. vulneris

Human infection

M. timonense

Human infection

M. bouchedurhonense

?: yet to be confirmed.

\section{Taxonomy of M. avium and Other Mycobacterial Species Belonging to MAC}

In the past, the classification of mycobacteria was based upon different morphological and phenotypic characteristics of individual mycobacterial species. The classic approach uses the scheme according to Runyon that differentiates mycobacterial species on the basis of colony growth rate and ability to form pigments of different colors [15]. In the last two decades, there has been a huge expansion of molecularbased methods, which has facilitated the discovery of new mycobacterial species and has led to changes in taxonomic classification [6]. Two major taxonomic groups of clinical significance are MTC and MAC (Table 1).
Seven out of the eight members of the first group (MTC) can cause disease in humans. In the Czech Republic $M$. tuberculosis, M. bovis, M. caprae, and M. pinnipedii have been isolated from humans and from animals [16, 17]. The incidence of human tuberculosis shows a decreasing trend in the Czech Republic, but there are new threats in the form of multidrug resistant forms of the disease. Human tuberculosis caused by $M$. bovis was no longer important after the eradication of bovine tuberculosis in cattle in 1968, although sporadic cases in humans still occur in the Czech Republic [17].

In the past, serotyping was widely used to characterize members of the MAC. A total of 28 serotypes have been described [18]. MAC species have lower pathogenicity in humans compared to the members of the MTC. These species are primarily found in the environment and in birds. The MAC comprises a number of slow-growing environmental and animal-associated mycobacterial species responsible for opportunistic human infections. The three main members are

(a) M. avium subsp. avium (serotypes 1-3 of former $M$. avium),

(b) M. avium subsp. hominissuis (serotypes 4-6, 8-11, and 21 of the former M. intracellulare),

(c) M. intracellulare (the remaining serotypes 7, 12-20, and 22-28 of MAC).

All these species are responsible for infections especially in birds and pigs [19]. Mycobacterium avium subsp. hominissuis (MAH) is the most commonly detected NTM causing infection in humans and pigs [19]. Mycobacterium avium subsp. avium (MAA) occasionally infects pigs and humans but is generally regarded as an obligate pathogen of birds, causing contagious avian tuberculosis [20]. Mycobacterium intracellulare (MI) is an environmental organism associated with lymphadenopathy (enlarged lymph nodes) in children and progressive pulmonary disease in elderly women [21]. MAC currently comprises seven additional species. $M$. chimaera (formerly sequevar MAC-A) and $M$. colombiense (formerly sequevar MAC-X) were first isolated from clinical samples from patients in Italy and Colombia $[22,23]$. M. vulneris was firstly described as a new species isolated from wound infection in elderly woman and from cervical lymphadenitis in two-year-old girl [24]. M. arosiense was recently uncovered as a cause of pulmonary infection and osteomyelitis $[25,26]$. First two cases of pulmonary infection associated with $M$. marseillense were reported two years later [27, 28]. Nowadays, only one case describing infection of $M$. timonense in an HIV positive man was reported [29]. Clinical relevance of $M$. bouchedurhonense is still unknown due to the clinically related but not confirmed isolate [30].

\section{Patterns of Human Infection Caused by M. avium Complex Agents}

The incidence of avian mycobacterioses in humans has shown an increasing tendency as human and bovine tuberculosis has begun to be eradicated in developed countries. This trend was also certainly affected by the development of diagnostic 
methods. It is possible to distinguish four forms of disease caused by mycobacteria belonging to the MAC.

3.1. Lung Disease. Lung disease is the most common form of infection caused by members of the MAC.

The most common and well-recognized pattern is cavitary disease, predominantly involving the upper lobes, similar to the pulmonary TB seen in sanitarium patients $[8,31]$. Patients with MAC lung disease tend to be older than TB patients and are not infectious for other humans [32]. They are predominantly male, often with a history of tobacco and/or alcohol abuse, and usually have underlying lung disease [33]. First large comprehensive study describing main patterns was published in 1979. Authors reported that $12 \%$ of patients with MAC demonstrated a reticular, fibrotic radiograph rather than cavitary disease. In contrast to the patients with cavitary disease, patients with fibronodular bronchiectasis are predominantly elderly women, often without a history of smoking or underlying lung disease [34]. Rare condition that can occur in young to middle aged patients is a solitary nodular lesion resembling tuberculoma or malignancy, indistinguishable by imaging [35]. Pleurisy caused by MAC is an uncommon recently recovered state $[36,37]$; in that case, the standard microbiological methods are decisive for an adequate treatment.

3.1.1. Hypersensitivity Pneumonitis-Like Illness (Hot Tub Lung). Many cases of other forms of lung disease resembling hypersensitivity pneumonitis (HP) started to be reported at the end of the last century $[38,39]$. The common denominator of these cases is the use of rehabilitation swimming pools and hot tubs before the onset of clinical symptoms. Simultaneously, MAC species have been isolated from clinical samples and from water environments. The pathogenesis of this so-called "hot tub lung" (HTL) is still disputed. Some authors indicate HTL as "hypersensitivity pneumonitis-like disease" [40]. The main emphasis is focused on the theory of hypersensitivity rather than on the infection caused by live MAC cells. Clinically, the disease first appears as flulike symptoms and gradually progresses to cough, shortness of breath, fever, and night sweats. The symptoms become worse after exposure to aerosols in the hot tub. Some patients experience healing after they avoid contaminated hot tubs or after corticosteroid remedy [38].

As pointed out by Agarwal and Nath, histopathological changes in the lungs of HP patients are different from changes presented by HTL patients [39]. The development of HP is accompanied by a histological triad (cellular bronchiolitis, chronic interstitial pneumonitis, and isolated small granulomas). Radiography of the chest usually discloses dominant interstitial inflammation with poorly defined granulomas. In contrast, HTL patients present strong and well-defined granulomas overshadowing interstitial inflammation.

The hypersensitivity reaction is probably triggered by antigens from both the living and dead MAC cells that enter the respiratory route through aerosols produced by air pumping in the hot tub. Similarly, other forms of pulmonary hypersensitivity are caused by inhalation of bacterial or fungal antigens or antigens from the environment: "humidifier lung," "farmer's lung," or "lung of pigeon breeders" [41].

3.2. Soft Tissue and Skin Lesions. Skin lesions are a rare form of disease caused by MAC. They occur particularly in patients with primary disease, which weakens their immune system (e.g., diabetes mellitus, cancer, chronic renal failure, HIV/AIDS, and Immune Reconstitution Inflammatory Syndrome (IRIS)). Infection results in plaques, nodular changes, and subcutaneous abscesses or can even resemble skin changes caused by leprosy [42, 43]. A spindle cell pseudotumor of the skin after infection by $M$. intracellulare was also reported [44].

3.3. Peripheral Lymphadenopathy. Another relatively common form of disease caused by MAC is peripheral lymphadenopathy, which mainly affects children [45]. Lymphonodal infection is typically an infantile disease affecting, in most cases unilaterally, cervical lymph nodes [46]. The route of infection is most likely oral, and the childhood habit of bringing hands and objects to the mouth may well explain the particular susceptibility of infants to this pathology [47]. The size of neck swelling, which is painless, varies considerably and fistulization is not rare.

Interestingly, BCG vaccination may provide protection against infections caused by members of the MAC. For example, discontinuation of a BCG vaccination program resulted in an increase in nontuberculous mycobacterial infections in the Czech Republic and Sweden [48-50]. Recent observations lend further strong support to this idea. Calmetization in the Czech Republic was finally stopped in 2010, before any case of MAC cervical lymphadenitis had been observed. From June 2014 to today, five cases of 3-4-year-old children (two girls and three boys) have been confirmed, only in the Moravian region (unpublished data).

In 2009, the first case of cervical lymphadenopathy in a young girl caused by $M$. colombiense was described. Previously, this species was only linked with cases of respiratory disease and disseminated infections [51].

3.4. Disseminated Infections. Disseminated MAC infections develop predominantly in severely immunocompromised people; the best known are those that affect HIV-infected patients [52]. The use of highly active antiretroviral therapy has reduced the incidence of opportunistic infections, including MAC [53]. However, the health status of some patients paradoxically deteriorates due to the IRIS. The restoration of immune function together with an augmentation of the levels of CD $4+$ T-cells in the blood could play a negative role, because the opportunistic infection, which is already present, may affect the formation of inflammatory responses, thus leading to disease. MAC members very often play a major role in this syndrome [54].

\section{Risk Factors for MAC Infection in Humans}

Adequate management of patient's case requires evaluating mycobacterial isolate together with further clinical circumstances (Table 2). Development of real infection relies on a 
TABle 2: Antibiotic treatment decision, clinical + laboratory findings.

(a) Pulmonary localization

\begin{tabular}{|c|c|c|c|c|}
\hline Signs & & $\begin{array}{l}\text { Laboratory } \\
\text { findings }\end{array}$ & & Signs \\
\hline Bronchiectasis & ++ & $\begin{array}{l}\text { Repeated } \\
\text { massive } \\
\text { isolation }\end{array}$ & +++ & $\begin{array}{c}\text { Cavitary, } \\
\text { HIV }\end{array}$ \\
\hline \multirow[t]{2}{*}{$\begin{array}{l}\text { Nonspecific, CF, } \\
\text { and } \mathrm{COPD}^{\dagger}\end{array}$} & $+/-^{*}$ & $\begin{array}{l}\text { Repeated } \\
\text { isolation }\end{array}$ & +++ & Systemic \\
\hline & - & Single isolation & $+^{*}$ & \\
\hline \multicolumn{5}{|c|}{$\begin{array}{cc}\text { Low benefit of antibiotic } & \\
\text { treatment versus adverse } & \text { Antibiotic } \\
\text { effects } & \text { treatment } \\
\text { Consider long-term } & \text { necessary } \\
\text { observation } & \\
\text { Supportive therapy } & \end{array}$} \\
\hline \multicolumn{5}{|c|}{$\begin{array}{c}\text { Colonization: COPD, CF, coniosis-mild course, mycobacterial } \\
\text { overgrowth-exacerbation; infection: chronic course, CT (RTG) } \\
\text { progressive changes, and systemic signs. }\end{array}$} \\
\hline
\end{tabular}

(b) Extrapulmonary localization

\begin{tabular}{|c|c|c|c|c|}
\hline Signs & & $\begin{array}{c}\text { Laboratory } \\
\text { findings }\end{array}$ & & Signs \\
\hline Skin, soft tissue & +++ & $\begin{array}{l}\text { Repeated } \\
\text { massive } \\
\text { isolation }\end{array}$ & +++ & $\begin{array}{c}\text { HIV, systemic } \\
\text { organs }\end{array}$ \\
\hline \multirow[t]{2}{*}{ Lymphadenitis } & ++ & $\begin{array}{l}\text { Repeated } \\
\text { isolation }\end{array}$ & ++ & $\begin{array}{c}\text { Osteoarticular, } \\
\text { tenosynovial }\end{array}$ \\
\hline & $+/-^{*}$ & $\begin{array}{c}\text { Single } \\
\text { isolation }\end{array}$ & + & \\
\hline \multicolumn{5}{|c|}{$\begin{array}{l}\text { AT therapy necessary } \\
\text { Lymphadenitis in children, skin: extirpation of affected lymph } \\
\text { nodes is of high importance, excision of affected tissue; } \\
\text { osteoarticular, tenosynovial, chirurgical debridement; HIV, } \\
\text { Haemocultivation. }\end{array}$} \\
\hline
\end{tabular}

${ }_{+++}^{+}$Strong recommendation for treatment.

${ }^{++}$Recommendation for treatment.

${ }^{+}$Weak recommendation for treatment (repeated sample collection necessary), managing intermittent treatment.

${ }^{-}$No treatment.

* Based on isolated MAC species. From invasively taken sample (biopsy, bronchoscopy).

${ }^{\dagger}$ Consider contamination, repeated exposition to environmental source, and household screening.

number of predisposing conditions (e.g., altered immunity status, infection dose).

4.1. Primary Disease. Alterations of cell immunity mechanisms can be divided to primal and acquired. Inherited (Mendelian) dysfunctions, primarily most serious, are based on inadequate cytokine (IL-12, INF- $\gamma$ ) production and pathway or receptor abnormalities. It could lead to disseminated disease or relapses after another exposition when manifested in early age [55]. Diabetes mellitus predisposes patients in a way of altered migration of phagocytes and low cytokine production/response [56].
Acquired alteration of cell immunity mechanisms arises from different conditions characterized by an impaired immune system: HIV/AIDS, postoperative period, therapy with TNF- $\alpha$ antagonists, and corticotherapy [57].

4.2. Secondary Disease. Functional weakness, lung tissue alteration, skeletal malformation of chest, and ciliary disorders lead to deterioration of self-cleaning function and physiological barriers, which are fundamental for effective elimination of microorganisms from lower respiratory tract. Airways obstruction, pathological changes of lung parenchyma such as fibrosis or necrosis by silicosis, smokers chronic obstructive pulmonary disease [58], cystic fibrosis [59], and niche created during former tuberculosis allows to microbial accumulation, surviving, and growth. Alteration of tissue, mucus, and inhaled pollution could negatively influence defense abilities of alveolar macrophages [60]. Such conditions allow mycobacteria to colonize respiratory tract on surface deposits in alveoli without interaction for long time. Microbial overgrowth and immunity response may lead to exacerbation of undelaying condition or true illness $[60,61]$.

True mycobacteriosis, contrary to tuberculosis, is result of comorbidities and coincidences.

\section{Treatment of MAC Infections}

Generally, prophylaxis, medical, and surgical treatment are three important aspects of management of infections due to NTM (Table 3, [62]). MAC is intrinsically resistant to many antibiotics and antituberculosis drugs. Due to the structure of cell wall and membrane impermeability, many traditional and well-tolerated antimicrobial drugs (e.g., beta lactams) are not effective against MAC. Isoniazid as classical representative of antituberculotics has for the same reason a little importance in proper treatment [63]. Active efflux and heterogeneous mutations in genome result in primary or inducible resistance to curative drugs as macrolides, rifamycins, or ethambutol $[64,65]$. To completely eradicate a mycobacterial infection with antibiotics requires that the course be long enough (at least 12 months) to act against bacteria that are dormant as well as active. Initial treatment of MAC disease should consist of two or more antimycobacterial drugs to prevent or delay the emergence of resistance [66]. Commonly used first-line drugs include macrolides (clarithromycin or azithromycin), ethambutol, and rifamycins (rifampin, rifabutin). Aminoglycosides, such as streptomycin and amikacin, are also used as additional agents [67].

5.1. Pulmonary MAC Infection. Guidelines stated by the American Thoracic Society recommend that most patients with pulmonary infection can be treated with a thriceweekly triple drug regimen of clarithromycin $(1000 \mathrm{mg})$ or azithromycin (500 mg), rifampin (600 mg), and ethambutol $(25 \mathrm{mg} / \mathrm{kg})$. Therapy should be continued for at least one year after culture results revert to negative [8]. In addition, the guidelines suggest the addition of amikacin or streptomycin thrice weekly early in the course of 
TABLE 3: Antibiotic regimes, summarization.

\begin{tabular}{|c|c|c|c|}
\hline & Combination & Duration & Comments \\
\hline \multicolumn{4}{|c|}{ Pulmonary } \\
\hline $\begin{array}{l}\text { Cavitary disease } \\
\text { Pneumonia }\end{array}$ & $\begin{array}{l}\text { Clarithromycin } 500-1000 \mathrm{mg} / \mathrm{d} \\
\text { or } \\
\text { Azithromycin } 250-300 \mathrm{mg} / \mathrm{d} \\
\text { Rifampicin } 450-600 \mathrm{mg} / \mathrm{d}\end{array}$ & $\begin{array}{l}\text { Up to } 12 \text { months, negative culture } \\
\text { Initial administration of } \\
\text { injectable agents for } 8 \text { to } 12 \text { weeks } \\
\text { Streptomycin } \\
(10-15 \mathrm{mg} / \mathrm{kg} / 3 \mathrm{x} / \mathrm{week}) \\
\text { Amikacin } 8-25 \mathrm{mg} / \mathrm{kg} 2-3 \text { times } \\
\text { weekly }\end{array}$ & $\begin{array}{l}\text { In case of macrolide resistance or } \\
\text { intolerance clofazimine and } \\
\text { quinolones may be useful based } \\
\text { on strain resistance profiles }\end{array}$ \\
\hline $\begin{array}{l}\text { Bronchiectatic-fibronodular } \\
\text { CF, COPD }\end{array}$ & $\begin{array}{l}\text { Clarithromycin } 1000 \mathrm{mg} / \mathrm{d} \text { or } \\
\text { Azithromycin } 500-600 \mathrm{mg} / \mathrm{d} \\
\text { Ethambutol } 25 \mathrm{mg} / \mathrm{kg} \\
\text { Rifampicin } 600 \mathrm{mg}\end{array}$ & $\begin{array}{l}\text { Intermittent three times weekly } \\
\text { In nonresponsive output change } \\
\text { to daily dosage }\end{array}$ & $\begin{array}{l}\text { Adjuvant therapy of underlying } \\
\text { disease, bronchodilators, airways } \\
\text { clearance support, smoking } \\
\text { cessation, and nutrition }\end{array}$ \\
\hline Hypersensitivity & Prednisone $1-2 \mathrm{mg} / \mathrm{kg} /$ daily & $\begin{array}{l}4-8 \text { weeks, repeated exposure } \\
\text { must be avoided }\end{array}$ & $\begin{array}{l}\text { Long postexposure observation } \\
\text { to exclude lung disease } \\
\text { progression }\end{array}$ \\
\hline \multicolumn{4}{|c|}{ Extrapulmonary } \\
\hline $\begin{array}{l}\text { Systemic, disseminated, and HIV } \\
\text { infection }\end{array}$ & $\begin{array}{l}\text { Clarithromycin } 500 \mathrm{mg} / \text { twice } \\
\text { daily or } \\
\text { Azithromycin } 1200 \mathrm{mg} / \text { daily } \\
\text { Rifabutin } 300 \mathrm{mg} / \mathrm{d} \\
\text { Ethambutol } 15 \mathrm{mg} / \mathrm{kg} \text { daily }\end{array}$ & $\begin{array}{l}\text { Up to } 12 \text { months } \\
\text { Initial administration of } \\
\text { injectable agents for } 8 \text { to } 12 \text { weeks } \\
\text { Streptomycin } \\
(10-15 \mathrm{mg} / \mathrm{kg} / 3 \mathrm{x} / \text { week }) \\
\text { Amikacin } 8-25 \mathrm{mg} / \mathrm{kg} 2-3 \text { times } \\
\text { weekly }\end{array}$ & $\begin{array}{l}\text { Prevention } \\
\text { Azithromycin } 500 \mathrm{mg} / \text { daily } \\
\text { Ethambutol } 15 \mathrm{mg} / \mathrm{kg} \text { daily } \\
\text { or } \\
\text { Clarithromycin } 500 \mathrm{mg} / \text { twice } \\
\text { daily +/- } \\
\text { Rifabutin } 300 \mathrm{mg} / \text { daily, HIV } \\
\text { with < } 50 \text { CD4 cells/L }\end{array}$ \\
\hline $\begin{array}{l}\text { Skin, soft tissue, and osteoarticular } \\
\text { disease }\end{array}$ & $\begin{array}{l}\text { Chirurgical debridement, } \\
\text { excision } \\
\text { Support: } \\
\text { Clarithromycin } 500-1000 \mathrm{mg} / \mathrm{d} \\
\text { or } \\
\text { Azithromycin } 250-300 \mathrm{mg} / \mathrm{d} \\
\text { Rifampicin } 450-600 \mathrm{mg} / \mathrm{d}\end{array}$ & $\begin{array}{l}\text { In case of indolent persistence, } \\
\text { supportive in more excessive } \\
\text { involvement: } \\
\text { Streptomycin } \\
(10-15 \mathrm{mg} / \mathrm{kg} / 3 \mathrm{x} / \text { week }) \\
\text { Amikacin } 8-25 \mathrm{mg} / \mathrm{kg} 2-3 \text { times } \\
\text { weekly }\end{array}$ & \\
\hline Lymphadenitis & $\begin{array}{l}\text { Complete extirpation } \\
\text { Support: } \\
\text { Clarithromycin } \\
\text { Rifampicin }\end{array}$ & $\begin{array}{l}\text { Duration and dosage not } \\
\text { established, see pulmonary, } \\
\text { consider Ethambutol with } \\
\text { caution in infants! }\end{array}$ & $\begin{array}{l}\text { Antibiotic treatment only in } \\
\text { cases where extirpation is } \\
\text { contraindicated or with poor } \\
\text { outcome after surgery, } \\
\text { considering superinfection with } \\
\text { other microorganisms }\end{array}$ \\
\hline
\end{tabular}

treatment (initial 2-3 months) in patients with severe lung disease. Fluoroquinolones should be used as second-line agents against MAC because of the poor outcome associated with them compared with macrolide-containing regimens [8].

5.2. Soft Tissue and Disseminated MAC Infection. The most active regimen according to the current guidelines seems to be a combination of clarithromycin (500 $\mathrm{mg}$ twice daily) and ethambutol ( $15 \mathrm{mg} / \mathrm{kg}$ daily) with or without rifabutin (300 mg daily). Azithromycin (500-600 mg daily) can be substituted for clarithromycin [8]. The addition of rifabutin has been recommended, especially in patients with advanced immunosuppression and high mycobacterial loads in blood or in the absence of effective antiretroviral therapy. Based on experience in patients without HIV infection, the guidelines suggest the use of amikacin or streptomycin as third or fourth drugs in these patients [68].
5.3. MAC Lymphadenitis. Antimicrobial treatment has a generally poor outcome, and a successful healing process in most cases may be supported by surgical excision of the lymph nodes involved [47]. The intervention, however, resolves the situation in $80 \%$ of cases, with the remaining $20 \%$ being characterized by relapse. Antibiotics are generally not required but may be beneficial in patients with extensive lymphadenitis or with a poor response to surgical therapy [69].

5.4. Chemoprophylaxis. Because $40 \%$ of patients with advanced HIV disease are likely to develop disseminated MAC, it makes sense to develop a strategy for preventing this disease in patients at risk [62]. The drug of choice is either clarithromycin $1000 \mathrm{mg}$ per day or azithromycin $1200 \mathrm{mg}$ per week [66].

5.5. Resistance to Macrolides. Administration of other effective drugs must necessarily be based on a sensitivity testing. In 
cases of rifamycins or macrolide resistance, clofazimine and quinolones instead or in combination with other sensitive drugs have proven good outcome [70].

\section{Infection of Animals Caused by Members of the M. avium Complex}

MAC members are widely distributed in the environment and have been isolated from soil, wastewater, water tanks, aerosols, protozoa, vegetation, animals, and humans [68]. Mycobacteria belonging to the MAC can affect a wide range of wild animals, but little has been published on the clinical signs, which are rarely perceived or not documented.

MAA is one of the causative agents of avian mycobacteriosis in birds. Domestic poultry are highly susceptible to MAA and are often the first to contract the disease, acting as a primary reservoir for the bacterium $[71,72]$. Other than birds, MAA infection has been reported in various other mammalian species, including small rodents, dogs, cats, pigs, cattle, and horses [73-76]. Mammals are, however, affected only sporadically [73]. Direct transmission between infected animals supports the classification of MAA as a zoonotic agent [71].

In contrast, sources of MAH and MI are mainly various components of the environment, which are under certain circumstances massively contaminated by these agents [77]. Transfer of these two mycobacterial species between infected animals has been reported sporadically [6]. MAH has also been isolated from lesions in deer and MI was also found in deer species although not as commonly and infection is usually subclinical [78].

The spread of MAC-caused disease in herds of livestock poses a big threat to the breed. Considerable spread of the causative agent not only to animals but also in the environment could occur during the long incubation period of the disease. Under such circumstances, the disease agent can become a source of infection for newborns and also for other animals of various species [79]. The clinical significance of individual MAC members varies between livestock species. Domestic poultry is highly susceptible to infection with $M$. avium, the causative agent of avian tuberculosis [80]. The disease is occasionally observed in the small-scale backyard breeding of poultry [71]. In commercial poultry farms, the disease has been eradicated due to the rapid turnover of flocks and good hygienic conditions. In general, three forms of disease caused by M. avium are observed in birds:

(a) granulomatous lesions in various organs,

(b) "paratuberculosis" form with lesions in the intestinal tract, accompanied by excretion of high doses of microorganisms,

(c) atypical form, which is usually observed in finches, canaries, and small parrots.

Regarding infection of MAC in pigs, MAH is the absolutely most isolated pathogen, while MAA is not so often detected. MAH infection in pigs usually has no clinical signs but can pose economic problems. MAH causes pathological changes most commonly in the mesenteric, head, or neck lymph nodes. Such affected parenchymal organs or sometimes the whole body of the animal is then confiscated by the veterinary authority. The source of infection for pigs is mainly an external environment (bedding, feed, feed water, soil, etc.) contaminated by droppings of wild birds or small terrestrial mammals $[77,81]$.

Horses are relatively resistant to MAC infections. Documented cases of MAA infection in horses have shown mainly granulomatous inflammation of various lymph nodes, intestine, and parenchymatous organs or tuberculous changes in the vertebrae [82]. In contrast, MAH infection in horses usually results in diffuse granulomatous enterocolitis, infliction of lung and lymph nodes, or even disseminated tuberculous changes in many organ systems, including the eye and heart [83].

Tuberculous lesions caused by $M$. avium in cattle are indistinguishable from lesions induced by $M$. bovis, which could complicate the diagnosis of new cases of $M$. bovis in countries free of bovine tuberculosis [84]. Granulomatous lesions are mainly localized in the lymph nodes of the digestive and respiratory systems [85], although cases of generalized disease have also been documented [74]. Ruminants are not infected by MAC members as frequently as by MAP, whose role in the pathogenesis of Crohn's disease in humans is still under discussion [86]. MAP is the causal agent of a chronic inflammation of the intestine in ruminants termed paratuberculosis (Johne's disease). In infected animals, it causes emaciation accompanied by diarrhoea, which can end with the death of the animal. The economic losses in infected cattle herds, especially in dairy herds, are enormous [87].

Hobby breed animals as dogs and cats are rarely infected by members of the MAC. The development of the disease is mainly associated with immunocompromised animals. MAC infections in cats were usually associated with both cutaneous lesions and generalized disease [88, 89].

Dogs possess a relatively high natural resistance to infection with MAC. However, a few sporadic occurrences of M. avium infections in dogs in the form of pulmonary, gastrointestinal, cutaneous, and disseminated lesions have been reported [90].

Today, red deer are often held in differently sized herds on pastures. The lack of a forest area stresses the animals, leading to an increased sensitivity to various diseases, including infections caused by M. avium [91].

\section{Sources of MAC for Humans}

Surface and drinking waters are naturally inhabited by multiple mycobacterial species and thus this environment could form an important part of the transmission route leading to MAC infection in humans [48]. MAH and MI are especially abundant in natural habitats, such as biofilms and sediments in rivers, ponds, and reservoirs with drinking water $[45,69]$. Moreover, there are many reports on the isolation of potentially pathogenic mycobacteria (including MAC) from water systems in households and hospitals [92]. Biofilm formation, amoeba-associated lifestyle, and resistance to chlorine have been recognized as important factors that contribute to the 
TABLE 4: The most frequent sequencing targets used for identification of nontuberculous mycobacteria.

\begin{tabular}{|c|c|c|c|c|c|}
\hline $\begin{array}{l}\text { Target } \\
\text { gene }\end{array}$ & Name & $\begin{array}{l}\text { Primer } \\
\text { type }\end{array}$ & Sequence $5^{\prime} \rightarrow 3^{\prime}$ & Length of the product (bp) & Reference \\
\hline $16 S r R N A$ & $\begin{array}{c}16 S 27 f \\
16 S 907 r\end{array}$ & $\begin{array}{l}\text { Forward } \\
\text { Reverse }\end{array}$ & $\begin{array}{l}\text { AGAGTTTGATCMTGGCTCAG } \\
\text { CCGTCAATTCMTTTRAGTTT }\end{array}$ & 921 & Harmsen et al., 2003 [12] \\
\hline hsp65 & $\begin{array}{l}\text { Tb11 } \\
\text { Tb12 }\end{array}$ & $\begin{array}{l}\text { Forward } \\
\text { Reverse }\end{array}$ & $\begin{array}{l}\text { ACCAACGATGGTGTGTCCAT } \\
\text { CGGATCACTCGTGAACGCTA }\end{array}$ & 441 & Telenti et al., 1993 [13] \\
\hline ITS & $\begin{array}{c}16 S-1511 f \\
23 S-23 r\end{array}$ & $\begin{array}{l}\text { Forward } \\
\text { Reverse }\end{array}$ & $\begin{array}{c}\text { AAGTCGTAACAAGGTARCCG } \\
\text { TCGCCAAGGCATCCACC }\end{array}$ & Approx. $380^{*}$ & Harmsen et al., 2003 [12] \\
\hline rpoB & $\begin{array}{l}\text { Myco-F } \\
\text { Myco-R }\end{array}$ & $\begin{array}{l}\text { Forward } \\
\text { Reverse }\end{array}$ & $\begin{array}{l}\text { GGCAAGGTCACCCCGAAGGG } \\
\text { AGCGGCTGCTGGGTGATCATC }\end{array}$ & 764 & Adékambi et al., 2003 [14] \\
\hline
\end{tabular}

*Amplicon size is not uniform due to the $16 \mathrm{~S}-23 \mathrm{~S}$ spacer length variability.

survival, colonization, and persistence of MAC in water distribution systems $[93,94]$.

\section{Diagnostic Techniques}

The diagnosis of MAC is based on clinical signs, postmortem gross lesions in animals, culture, and also acid-fast staining or biopsy samples of fluids or organs.

8.1. Microbiology-Based Methods. The basic method for detection of mycobacteria remains cultivation using solid and liquid media [95]. MAC grows best in egg based media and special agar media. The optimal incubation temperature for MAC species is $37^{\circ} \mathrm{C}-40^{\circ} \mathrm{C}$. Culture can be performed in Dorset's and Herrold's egg yolk medium, Middlebrook 7H10 and $7 \mathrm{H} 11$ agar $[20,96]$. Cultures should be incubated for at least 8 weeks. Nonsterile specimens need to be processed with detergent, alkali, or acid to eliminate rapidly-growing microorganisms. Incubation with various decontamination agents such as $0.6-0.75 \%$ hexadecylpyridinium chloride (HPC) or $\mathrm{NaOH}$ has been practiced. It is important that decontamination does not remove too many viable Mycobacterium cells [97]. Shorter incubation times can be achieved using automated broth based systems, like the liquid culture BACTEC system MGIT 960 [98]. These systems have been reported to be highly sensitive for culture [98].

Identification of mycobacterial isolates can be based on growth rates, colony pigmentation, and biochemical tests such as niacin production, nitrate reduction, tween 80 hydrolysis, and growth on MacConkey or sodium chloride tolerance [62]. The use of this approach for MAC members is limited due to the variable results for the majority of the applied tests. Conventional biochemical tests for species identification are time-consuming and fail to distinguish between $M$. avium and M. intracellulare [96].

Matrix-assisted laser desorption ionization-time of flight mass spectrometry (MALDI-TOF MS) is a rapid and highly promising tool for rapid primary differentiation of mycobacteria. However, routine identification is still hampered by the lack of procedure standardization and the small size of databases, even though some progress has been made in the development of new protocols. The accuracy of typing MAC subspecies by MADI-TOF can also be influenced by small differences in ribosomal protein structure [99].
8.2. Molecular-Based Methods. The development of molecular-based methods has enabled the differentiation of members within the MAC.

8.2.1. Detection Kits Based on Hybridization Probes. Several commercial methods for the detection of mycobacteria using hybridization probes are available, including the AccuProbe system (Genprobe, San Diego, Calif), INNO-LiPA (Innogenetics, Ghent, Belgium), or GenoType Mycobacterium assay (Hain, Lifescience, Germany). Such tests can provide the desirable sensitivity and specificity but are very often limited to the identification of a small number of mycobacteria [100].

8.2.2. Mycobacterial Broad-Range PCR Detection and Subsequent Sequence Analysis. Most mycobacterial species still lack known specific DNA loci suitable for PCR detection. Generally, broad-range PCR detection is targeted at common shared bacterial genes (via genus-specific primers), and subsequently, direct sequencing (Table 4) and sequence homology analysis are used to detect and differentiate mycobacteria [101]. Amplification of the gene to be sequenced preferably uses DNA extracted from a pure bacterial culture but can be achieved also directly from a clinical sample [102].

The first choice is generally the $16 S \mathrm{rRNA}$ gene [12], but the use of this target does not allow the discrimination of different MAC members. Other more variable regions are preferably used as second-step sequencing targets: for example, the internal transcribed spacer (ITS), for the differentiation of the members of the Mycobacterium avium-intracellulare complex, and the $\operatorname{rpoB}$, for the rapidly-growing mycobacteria $[19,103]$.

8.2.3. Species-Specific PCR Detection of Mycobacteria. Some MAC species can be differentiated based on the detection of insertion sequences (IS). The genome of MAA harbors the specific insertion sequence IS901 and a low number of copies of IS1245 [85, 104]. In contrast, MAH lacks IS901 and usually contains a high number of IS1245 [19]. The genome of MI does not contain the aforementioned IS elements [105].

8.2.4. Genotyping Methods of M. avium. Molecular epidemiology is one of the areas in mycobacterial research which is widely used to study the transmission epidemics and 
outbreaks. It exploits the presence of various polymorphisms in the genome of the bacteria that can be widely used as genetic markers. Molecular-based techniques used in epidemiological studies to identify the source and origin of MAC infection are very well established in veterinary medicine. In human patients, however, such studies are performed only occasionally. Isolates can be typed using analysis of the restriction fragment length polymorphism (RFLP) pattern in the amplified IS1245, IS1311 (MAH; [106]), or IS901 (MAA, [107]). Another option is the typing of variablenumber tandem repeats (VNTRs) of genetic elements called mycobacterial interspersed repetitive units (MIRUs) using PCR analysis [108].

8.2.5. Next Generation Sequencing Technologies. A new prospect towards molecular epidemiology was introduced with the development of the next generation sequencing (NGS) methods, where the entire genome is sequenced which not only helps in pointing out minute differences between the various sequences but also saves time and the cost. NGS is also found to be useful in metagenomics studies, comparative genomics, and also various aspects about transmission dynamics. These techniques enable the identification of mycobacterial strains and also facilitate the study of their phylogenetic and evolutionary traits. Various platforms of NGS are being used widely (e.g., Illumina/Solexa Genome Analyzer; Applied Biosystems Ion Torrent; Helicos Heliscope $^{\mathrm{TM}}$; Pacific Biosciences Single Molecule Real Time, SMRT).

As whole genome sequencing (WGS) becomes popular and implemented to research laboratories, new data with mycobacterial genomes were released and published [109, 110]. The comparison of whole genomic sequences obtained for relatively very close mycobacterial species would bring additional data useful for improvement of molecular-based bacterial typing. WGS is considered as an important tool to determine sequence variation at a real epidemiological scale, to determine the evolutionary relationship of the strains and also to determine the source of infection and the transmission of the disease between various patients [111]. WGS may become the gold standard for typing various strains for ME but there are certain limitations such as the need for specialized software to analyze the various sequence reads produced and the incomplete understanding of the genome variance.

\section{Conclusions}

The MAC comprises slow-growing mycobacteria that are ubiquitous in the environment, have a wide source range, and cause disease in a variety of domestic or wild animals and humans. The epidemiology of MAC infections is unclear in many cases, although colonization of the environment (mainly by MAH and MI) is well known and the prevalence of the disease in humans is increasing. Routes of transmission have not been clearly identified and transmission from human to human has yet to be convincingly demonstrated. The environment is the main source of MAC infections in humans.
Evidence for zoonotic potential should not be neglected, particularly with regard to immunocompromised patients. Recent reports, suggesting an association between MAC and autoimmune and other chronic human diseases, underline the importance of further research on MAC biology, diagnosis, and epidemiology.

Finally, it is critical to understand the impact of MAC in public health and to determine transmission routes between humans and wildlife. Such studies will require interdisciplinary collaboration among veterinary, medical, and other public health officials.

\section{Competing Interests}

The authors declare that they have no competing interests.

\section{Acknowledgments}

The work was supported by the Ministry of Education, Youth and Sports of the Czech Republic (Grant LO1218). Neysan Donnelly is thanked for the grammatical correction of the paper.

\section{References}

[1] J. P. Euzéby, "List of bacterial names with standing in nomenclature: a folder available on the internet," International Journal of Systematic Bacteriology, vol. 47, no. 2, pp. 590-592, 1997.

[2] J. O. Falkinham III, "Surrounded by mycobacteria: nontuberculous mycobacteria in the human environment," Journal of Applied Microbiology, vol. 107, no. 2, pp. 356-367, 2009.

[3] "Commission Decision of March 31, 2004 amending decisions 93/52/EEC, 2001/618/EC and 2003/467/EC as regards the status of acceding countries with regard to brucellosis (B. melitensis), Aujeszky's disease, enzootic bovine leukosis, bovine brucellosis and tuberculosis and of France with regard to Aujeszky's disease (notified under document number C(2004) 1094) (text with EEA relevance, 2004/320/EC)," Official Journal of European Communication, vol. 102, p. 75, 2004.

[4] I. Trcka, J. Lamka, R. Suchy et al., "Mycobacterial infections in European wild boar (Sus scrofa) in the Czech Republic during the years 2002 to 2005," Veterinarni Medicina, vol. 51, no. 5, pp. 320-332, 2006.

[5] N. M. Shah, J. A. Davidson, L. F. Anderson et al., "Pulmonary Mycobacterium avium-intracellulare is the main driver of the rise in non-tuberculous mycobacteria incidence in England, Wales and Northern Ireland, 2007-2012," BMC Infectious Diseases, vol. 16, no. 1, article 195, 2016.

[6] J. Kazda, "The classification of mycobacteria with regard to their ecology," in The Ecology of Mycobacteria: Impact on Animal's and Human's Health, J. Kazda, I. Pavlik, J. O. Falkinham III, and K. Hruska, Eds., pp. 9-10, Springer, Berlin, Germany, 1st edition, 2009.

[7] R. Schulze-Röbbecke, B. Janning, and R. Fischeder, "Occurrence of mycobacteria in biofilm samples," Tubercle and Lung Disease, vol. 73, no. 3, pp. 141-144, 1992.

[8] D. E. Griffith, T. Aksamit, B. A. Brown-Elliott et al., "An official ATS/IDSA statement: diagnosis, treatment, and prevention of nontuberculous mycobacterial diseases," American Journal of 
Respiratory and Critical Care Medicine, vol. 175, no. 4, pp. 367416, 2007.

[9] E. Tortoli, “The new mycobacteria: an update," FEMS Immunology and Medical Microbiology, vol. 48, no. 2, pp. 159-178, 2006.

[10] J. L. Cook, "Nontuberculous mycobacteria: opportunistic environmental pathogens for predisposed hosts," British Medical Bulletin, vol. 96, no. 1, pp. 45-59, 2010.

[11] P. MacEk, M. Bodnarova, J. Zavada et al., "Mycobacterium marinum epididymoorchitis: case report and literature review," Urologia Internationalis, vol. 87, no. 1, pp. 120-124, 2011.

[12] D. Harmsen, S. Dostal, A. Roth et al., "RIDOM: Comprehensive and public sequence database for identification of Mycobacterium species," BMC Infectious Diseases, vol. 3, article 26, 2003.

[13] A. Telenti, F. Marchesi, M. Balz, F. Bally, E. C. Bottger, and T. Bodmer, "Rapid identification of mycobacteria to the species level by polymerase chain reaction and restriction enzyme analysis," Journal of Clinical Microbiology, vol. 31, no. 2, pp. 175178, 1993.

[14] T. Adékambi, P. Colson, and M. Drancourt, "rpoB-based identification of nonpigmented and late-pigmenting rapidly growing mycobacteria," Journal of Clinical Microbiology, vol. 41, no. 12, pp. 5699-5708, 2003.

[15] E. H. Runyon, "Pathogenic mycobacteria," Advanced Tuberculosis Research, vol. 14, pp. 235-287, 1965.

[16] I. Pavlik, L. Dvorska, M. Bartos et al., "Molecular epidemiology of bovine tuberculosis in the Czech Republic and Slovakia in the period 1965-2001 studied by spoligotyping," Veterinarni Medicina, vol. 47, no. 7, pp. 181-194, 2002.

[17] I. Pavlik, W. Y. Ayele, M. Havelkova, M. Svejnochova, V. Katalinic-Jankovic, and M. Zolnir-Dovc, "Mycobacterium bovis in human population in four Central European countries during 1990-1999," Veterinarni Medicina, vol. 48, no. 4, pp. 9098, 2003.

[18] E. Wolinsky and W. B. Schaefer, "Proposed numbering scheme for mycobacterial serotypes by agglutination," International Journal of Systematic Bacteriology, vol. 23, no. 2, pp. 182-183, 1973.

[19] W. Mijs, P. de Haas, R. Rossau et al., "Molecular evidence to support a proposal to reserve the designation Mycobacterium avium subsp. avium for bird-type isolates and ' $M$. avium subsp. hominissuis' for the human/porcine type of M. avium," International Journal of Systematic and Evolutionary Microbiology, vol. 52, no. 5, pp. 1505-1518, 2002.

[20] L. A. Tell, L. Woods, and R. L. Cromie, "Mycobacteriosis in birds," Revue Scientifique et Technique, vol. 20, no. 1, pp. 180203, 2001.

[21] A. M. Kyriakopoulos, P. T. Tassios, P. Matsiota-Bernard, E. Marinis, S. Tsaousidou, and N. J. Legakis, "Characterization to species level of Mycobacterium avium complex strains from human immunodeficiency virus-positive and -negative patients," Journal of Clinical Microbiology, vol. 35, no. 11, pp. 3001-3003, 1997.

[22] E. Tortoli, L. Rindi, M. J. Garcia et al., "Proposal to elevate the genetic variant MAC-A, included in the Mycobacterium avium complex, to species rank as Mycobacterium chimaera sp. nov.", International Journal of Systematic and Evolutionary Microbiology, vol. 54, no. 4, pp. 1277-1285, 2004.

[23] M. I. Murcia, E. Tortoli, M. C. Menendez, E. Palenque, and M. J. Garcia, "Mycobacterium colombiense sp. nov., a novel member of the Mycobacterium avium complex and description of MAC-X as a new ITS genetic variant," International Journal of Systematic and Evolutionary Microbiology, vol. 56, no. 9, pp. 2049-2054, 2006.

[24] J. Van Ingen, M. J. Boeree, K. Kösters et al., "Proposal to elevate Mycobacterium avium complex ITS sequevar MAC-Q to Mycobacterium vulneris sp. nov," International Journal of Systematic and Evolutionary Microbiology, vol. 59, no. 9, pp. 2277-2282, 2009.

[25] E. Tortoli, B. Adriani, S. Baruzzo et al., "Pulmonary disease due to Mycobacterium arosiense, an easily misidentified pathogenic novel mycobacterium," Journal of Clinical Microbiology, vol. 47, no. 6, pp. 1947-1949, 2009.

[26] D. Bang, T. Herlin, M. Stegger et al., "Mycobacterium arosiense sp. nov., a slowly growing, scotochromogenic species causing osteomyelitis in an immunocompromised child," International Journal of Systematic and Evolutionary Microbiology, vol. 58, no. 10, pp. 2398-2402, 2008.

[27] S.-Y. Kim, H. Yoo, B.-H. Jeong et al., "First case of nontuberculous mycobacterial lung disease caused by Mycobacterium marseillense in a patient with systemic lupus erythematosus," Diagnostic Microbiology and Infectious Disease, vol. 79, no. 3, pp. 355-357, 2014.

[28] A. Grottola, P. Roversi, A. Fabio et al., "Pulmonary disease caused by Mycobacterium marseillense, Italy," Emerging Infectious Diseases, vol. 20, no. 10, pp. 1769-1770, 2014.

[29] J. Zurita, D. Ortega-Paredes, M. Mora et al., "Characterization of the first report of Mycobacterium timonense infecting an HIV patient in an Ecuadorian hospital," Clinical Microbiology and Infection, vol. 20, no. 12, pp. 1113-1116, 2014.

[30] I. Ben Salah, C. Cayrou, D. Raoult, and M. Drancourt, “Mycobacterium marseillense sp. nov., Mycobacterium timonense sp. nov. and Mycobacterium bouchedurhonense sp. nov., members of the Mycobacterium avium complex," International Journal of Systematic and Evolutionary Microbiology, vol. 59, no. 11, pp. 2803-2808, 2009.

[31] S. C. Parrish, J. Myers, and A. Lazarus, "Nontuberculous mycobacterial pulmonary infections in non-HIV patients," Postgraduate Medicine, vol. 120, no. 4, pp. 78-86, 2008.

[32] H. E. Crow, C. T. King, C. E. Smith, R. F. Corpe, and I. Stergus, "A limited clinical, pathologic, and epidemiologic study of patients," American Review of Tuberculosis, vol. 75, no. 2, pp. 199-222, 1957.

[33] D. Y. Rosenzweig, "Pulmonary mycobacterial infections due to Mycobacterium intracellulare-avium complex: clinical features and course in 100 consecutive cases," Chest, vol. 75, no. 2, pp. 115-119, 1979.

[34] E. E. Christensen, G. W. Dietz, C. H. Ahn et al., "Pulmonary manifestations of Mycobacterium intracellularis," American Journal of Roentgenology, vol. 133, no. 1, pp. 59-66, 1979.

[35] T. Asakura, M. Ishii, M. Haraguchi et al., "Dry pleurisy complicating solitary pulmonary nodules caused by Mycobacterium avium: a case report," Journal of Medical Case Reports, vol. 9, no. 1, article 238, 2015.

[36] H. J. Yoon, M. J. Chung, K. S. Lee, J. S. Kim, H. Y. Park, and W. J. Koh, "Broncho-pleural fistula with hydropneumothorax at CT: diagnostic implications in Mycobacterium avium complex lung disease with pleural involvement," Korean Journal of Radiology, vol. 17, no. 2, pp. 295-301, 2016.

[37] A. Waness, "Rare cavitary MAC lung disease causing a serious broncho-pleural air leak in an immune competent patient," Journal of Medical Cases, vol. 4, no. 12, pp. 825-827, 2013.

[38] J. Embil, P. Warren, M. Yakrus et al., "Pulmonary illness associated with exposure to Mycobacterium-avium complex in hot 
tub water: Hypersensitivity pneumonitis or infection?" Chest, vol. 111, no. 3, pp. 813-816, 1997.

[39] R. Agarwal and A. Nath, "Hot-tub lung: hypersensitivity to Mycobacterium avium but not hypersensitivity pneumonitis," Respiratory Medicine, vol. 100, no. 8, p. 1478, 2006.

[40] A. Sood, R. Sreedhar, P. Kulkarni, and A. R. Nawoor, "Hypersensitivity pneumonitis-like granulomatous lung disease with nontuberculous mycobacteria from exposure to hot water aerosols," Environmental Health Perspectives, vol. 115, no. 2, pp. 262-266, 2007.

[41] M. Rosal-Sanchez, J. Alvarez, M. J. Torres, C. Mayorga, J. Pérez, and M. Blanca, "Pigeon Fancier's Lung after low exposure," Allergy, vol. 57, no. 7, p. 649, 2002.

[42] S. D. Lawn, T. A. Bicanic, and D. C. Macallan, "Pyomyositis and cutaneous abscesses due to Mycobacterium avium: an immune reconstitution manifestation in a patient with AIDS," Clinical Infectious Diseases, vol. 38, no. 3, pp. 461-463, 2004.

[43] R. Tandon, K. S. Kim, and R. Serrao, "Disseminated Mycobacterium avium-intracellulare infection in a person with AIDS with cutaneous and CNS lesions," AIDS Reader, vol. 17, no. 11, pp. 555-560, 2007.

[44] T. Shiomi, T. Yamamoto, and T. Manabe, "Mycobacterial spindle cell pseudotumor of the skin," Journal of Cutaneous Pathology, vol. 34, no. 4, pp. 346-351, 2007.

[45] T. P. Primm, C. A. Lucero, and J. O. Falkinham III, "Health impacts of environmental mycobacteria," Clinical Microbiology Reviews, vol. 17, no. 1, pp. 98-106, 2004.

[46] R. Hazra, C. D. Robson, A. R. Perez-Atayde, and R. N. Husson, "Lymphadenitis due to nontuberculous mycobacteria in children: Presentation and response to therapy," Clinical Infectious Diseases, vol. 28, no. 1, pp. 123-129, 1999.

[47] J. A. Lindeboom, E. J. Kuijper, E. S. B. Van Coppenraet, R. Lindeboom, and J. M. Prins, "Surgical excision versus antibiotic treatment for nontuberculous mycobacterial cervicofacial lymphadenitis in children: a multicenter, randomized, controlled trial," Clinical Infectious Diseases, vol. 44, no. 8, pp. 1057-1064, 2007.

[48] L. Trnka, D. Daňková, and E. Švandová, “Six years' experience with the discontinuation of BCG vaccination: 4. Protective effect of BCG vaccination against the Mycobacterium avium intracellulare complex," Tubercle and Lung Disease, vol. 75, no. 5, pp. 348-352, 1994.

[49] V. Romanus, H. O. Hallander, P. Wåhlén, A. M. OlinderNielsen, P. H. W. Magnusson, and I. Juhlin, "Atypical mycobacteria in extrapulmonary disease among children. Incidence in Sweden from 1969 to 1990, related to changing BCGvaccination coverage," Tubercle and Lung Disease, vol. 76, no. 4, pp. 300-310, 1995.

[50] J. Thegerström, V. Romanus, V. Friman, L. Brudin, P. D. Haemig, and B. Olsen, "Mycobacterium avium lymphadenopathy among children, Sweden," Emerging Infectious Diseases, vol. 14, no. 4, pp. 661-663, 2008.

[51] K. Vuorenmaa, I. B. Salah, V. Barlogis, H. Chambost, and M. Drancourt, "Mycobacterium colombiense and pseudotuberculous lymphadenopathy," Emerging Infectious Diseases, vol. 15, no. 4, pp. 619-620, 2009.

[52] F. Biet, M. L. Boschiroli, M. F. Thorel, and L. A. Guilloteau, "Zoonotic aspects of Mycobacterium bovis and Mycobacterium avium-intracellulare complex (MAC)," Veterinary Research, vol. 36, no. 3, pp. 411-436, 2005.

[53] P. Gona, R. B. Van Dyke, P. L. Williams et al., "Incidence of opportunistic and other infections in HIV-infected children in the HAART era," The Journal of the American Medical Association, vol. 296, no. 3, pp. 292-300, 2006.

[54] S. K. Field and R. L. Cowie, "Lung disease due to the more common nontuberculous mycobacteria," Chest, vol. 129, no. 6, pp. 1653-1672, 2006.

[55] S. Al-Muhsen and J.-L. Casanova, "The genetic heterogeneity of mendelian susceptibility to mycobacterial diseases," Journal of Allergy and Clinical Immunology, vol. 122, no. 6, pp. 1043-1051, 2008.

[56] C. E. Prasad, "Immunodeficiencies in diabetes and mycobacterial infections," International Journal of Diabetes in Developing Countries, vol. 19, pp. 52-55, 1999.

[57] J. R. Honda, V. Knight, and E. D. Chan, "Pathogenesis and risk factors for nontuberculous mycobacterial lung disease," Clinics in Chest Medicine, vol. 36, no. 1, pp. 1-11, 2015.

[58] C.-T. Huang, Y.-J. Tsai, H.-D. Wu et al., "Impact of nontuberculous mycobacteria on pulmonary function decline in chronic obstructive pulmonary disease," The International Journal of Tuberculosis and Lung Disease, vol. 16, no. 4, pp. 539-545, 2012.

[59] T. Qvist, M. Gilljam, B. Jönsson et al., "Epidemiology of nontuberculous mycobacteria among patients with cystic fibrosis in Scandinavia," Journal of Cystic Fibrosis, vol. 14, no. 1, pp. 46-52, 2015.

[60] R. Vlahos and S. Bozinovski, "Role of alveolar macrophages in chronic obstructive pulmonary disease," Frontiers in Immunology, vol. 5, article 435, 2014.

[61] R. N. Plotinsky, E. A. Talbot, and C. F. von Reyn, "Proposed definitions for epidemiologic and clinical studies of Mycobacterium avium complex pulmonary disease," PLoS ONE, vol. 8, no. 11, Article ID e77385, 2013.

[62] V. M. Katoch, "Infections due to non-tuberculous mycobacteria (NTM)," Indian Journal of Medical Research, vol. 120, no. 4, pp. 290-304, 2004.

[63] K. Mdluli, J. Swanson, E. Fischer, R. E. Lee, and C. E. Barry III, "Mechanisms involved in the intrinsic isoniazid resistance of Mycobacterium avium," Molecular Microbiology, vol. 27, no. 6, pp. 1223-1233, 1998.

[64] L. Rodrigues, D. Sampaio, I. Couto et al., "The role of efflux pumps in macrolide resistance in Mycobacterium avium complex," International Journal of Antimicrobial Agents, vol. 34, no. 6, pp. 529-533, 2009.

[65] D. E. Griffith, B. A. Brown-Elliott, B. Langsjoen et al., "Clinical and molecular analysis of macrolide resistance in Mycobacterium avium complex lung disease," American Journal of Respiratory and Critical Care Medicine, vol. 174, no. 8, pp. 928934, 2006.

[66] C. A. Benson, P. L. Williams, J. S. Currier et al., "A prospective, randomized trial examining the efficacy and safety of clarithromycin in combination with ethambutol, rifabutin, or both for the treatment of disseminated Mycobacterium avium complex disease in persons with acquired immunodeficiency syndrome," Clinical Infectious Diseases, vol. 37, no. 9, pp. 12341243, 2003.

[67] S. H. Kasperbauer and C. L. Daley, "Diagnosis and treatment of infections due to Mycobacterium avium complex," Seminars in Respiratory and Critical Care Medicine, vol. 29, no. 5, pp. 569576, 2008.

[68] J. E. Kaplan, C. Benson, K. K. Holmes, J. T. Brooks, A. Pau, and H. Masur, "Guidelines for prevention and treatment of opportunistic infections in HIV-infected adults and adolescents: 
recommendations from CDC, the National Institutes of Health, and the HIV Medicine Association of the Infectious Diseases Society of America," Morbidity and Mortality Weekly Report, vol. 58, no. 4, pp. 1-198, 2009.

[69] J. A. Lindeboom, E. J. Kuijper, E. S. B. van Coppenraet, R. Lindeboom, and J. M. Prins, "Surgical excision versus antibiotic treatment for nontuberculous mycobacterial cervicofacial lymphadenitis in children: a multicenter, randomized, controlled trial," Clinical Infectious Diseases, vol. 44, no. 8, pp. 1057-1064, 2007.

[70] S. Fournier, A. M. Burguière, A. Flahault, V. Vincent, M. P. Treilhou, and M. Eliaszewicz, "Effect of adding clofazimine to combined clarithromycin-ethambutol therapy for Mycobacterium avium complex septicemia in AIDS patients," European Journal of Clinical Microbiology and Infectious Diseases, vol. 18, no. 1, pp. 16-22, 1999.

[71] J. E. Shitaye, L. Matlova, A. Horvathova et al., "Mycobacterium avium subsp. avium distribution studied in a naturally infected hen flock and in the environment by culture, serotyping and IS901 RFLP methods," Veterinary Microbiology, vol. 127, no. 12, pp. 155-164, 2008.

[72] H. Gerlach, "Mycobacterium," in Avian Medicine: Principles and Application, B. W. Ritchie, G. J. Harrison, and L. R. Harrison, Eds., pp. 971-975, Wingers, Lake Worth, Fla, USA, 1994.

[73] M. F. Thorel, H. Huchzermeyer, R. Weiss, and J. J. Fontaine, "Mycobacterium avium infections in animals," Veterinary Research, vol. 28, no. 5, pp. 439-447, 1997.

[74] M. F. Thorel, H. F. Huchzermeyer, and A. L. Michel, "Mycobacterium avium and Mycobacterium intracellulare infection in mammals," Revue Scientifique et Technique, vol. 20, pp. 204-218, 2001.

[75] M. Ocepek, M. Pate, M. Zolnir-Dovc, and Z. Cvetnic, “Tuberculosis in cattle caused by IS901+ Mycobacterium avium subsp. avium - a case report," Veterinarni Medicina, vol. 48, no. 1-2, pp. 47-50, 2003.

[76] V. Haist, F. Seehusen, I. Moser et al., "Mycobacterium avium subsp. hominissuis infection in 2 pet dogs, Germany," Emerging Infectious Diseases, vol. 14, no. 6, pp. 988-990, 2008.

[77] L. Matlova, L. Dvorska, J. Bartl et al., "Mycobacteria isolated from the environment of pig farms in the Czech Republic during the years 1996 to 2002," Veterinarni Medicina, vol. 48, no. 12, pp. 343-357, 2003.

[78] W. Glawischnig, T. Steineck, and J. Spergser, "Infections caused by Mycobacterium avium subspecies avium, Hominissuis, and paratuberculosis in free-ranging red deer (Cervus elaphus hippelaphus) in Austria, 2001-2004," Journal of Wildlife Diseases, vol. 42, no. 4, pp. 724-731, 2006.

[79] M. Pate, M. Moravkova, B. Krt, I. Pavlik, and M. Ocepek, "Genotyping of Mycobacterium avium subsp. avium isolates from domestic animals in Slovenia by IS901 RFLP," Veterinarni Medicina, vol. 54, no. 6, pp. 270-279, 2009.

[80] K. Hejlícek and F. Treml, "Comparison of the pathogenesis and epizootiologic importance of avian mycobacteriosis in various types of domestic and free-living syntropic birds," Veterinarni Medicina, vol. 40, no. 6, pp. 187-194, 1995.

[81] M. Skoric, E. J. Shitaye, R. Halouzka et al., "Tuberculous and tuberculoid lesions in free living small terrestrial mammals and the risk of infection to humans and animals: a review," Veterinarni Medicina, vol. 52, no. 4, pp. 144-161, 2007.

[82] P. Kriz, P. Jahn, B. Bezdekova et al., "Mycobacterium avium subsp. hominissuis infection in horses," Emerging Infectious Diseases, vol. 16, no. 8, pp. 1328-1329, 2010.
[83] I. Pavlík, P. Jahn, L. Dvorska, M. Bartos, L. Novotny, and R. Halouzka, "Mycobacterial infections in horses: a review of the literature," Veterinarni Medicina, vol. 49, no. 11, pp. 427-440, 2004.

[84] C. O. Thoen, J. H. Steele, and M. J. Gilsdor, Eds., Mycobacterium bovis Infection in Animals and Humans, Blackwell Publishing, 2nd edition, 2006.

[85] L. Dvorska, T. J. Bull, M. Bartos et al., “A standardised restriction fragment length polymorphism (RFLP) method for typing Mycobacterium avium isolates links IS901 with virulence for birds," Journal of Microbiological Methods, vol. 55, no. 1, pp. 1127, 2003.

[86] J. L. Mendoza, R. Lana, and M. Díaz-Rubio, "Mycobacterium avium subspecies paratuberculosis and its relationship with Cronh's disease," World Journal of Gastroenterology, vol. 15, no. 4, pp. 417-422, 2009.

[87] L. Hasonova and I. Pavlik, "Economic impact of paratuberculosis in dairy cattle herds: a review," Veterinarni Medicina, vol. 51, no. 5, pp. 193-211, 2006.

[88] M. Barry, J. Taylor, and J. P. Woods, "Disseminated Mycobacterium avium infection in a cat," Canadian Veterinary Journal, vol. 43, no. 5, pp. 369-371, 2002.

[89] A. Griffin, A. L. Newton, L. R. Aronson, D. C. Brown, and R. S. Hess, "Disseminated Mycobacterium avium complex infection following renal transplantation in a cat," Journal of the American Veterinary Medical Association, vol. 222, no. 8, pp. 1097-1101, 2003.

[90] B. Horn, D. Forshaw, D. Cousins, and P. J. Irwin, "Disseminated Mycobacterium avium infection in a dog with chronic diarrhoea," Australian Veterinary Journal, vol. 78, no. 5, pp. 320325, 2000.

[91] M. Machackova-Kopecna, M. Bartos, M. Straka et al., "Paratuberculosis and avian tuberculosis infections in one red deer farm studied by IS900 and IS901 RFLP analysis," Veterinary Microbiology, vol. 105, no. 3-4, pp. 261-268, 2005.

[92] J. O. Falkinham III, M. D. Iseman, P. de Haas, and D. van Soolingen, "Mycobacterium avium in a shower linked to pulmonary disease," Journal of Water and Health, vol. 6, no. 2, pp. 209-213, 2008.

[93] V. Thomas and G. McDonnell, "Relationship between mycobacteria and amoebae: ecological and epidemiological concerns," Letters in Applied Microbiology, vol. 45, no. 4, pp. 349-357, 2007.

[94] I. Pagnier, D. Raoult, and B. La Scola, "Isolation and identification of amoeba-resisting bacteria from water in human environment by using an Acanthamoeba polyphaga co-culture procedure," Environmental Microbiology, vol. 10, no. 5, pp. 1135$1144,2008$.

[95] M. Kubin, B. Burianova, L. Mezensky, M. Slosarek, and M. Turzova, "Diagnostics of mycobacterial infections," in Microbiological Axamination Methods, J. Schindle, B. Tichacek, and V. Potuznik, Eds., vol. 3, pp. 32-42, Avicenum, Prague, Czech Republic, 1st edition, 1986.

[96] OIE, Avian tuberculosis 2010, 2010, http://www.oie.int/en/international-standard-setting/terrestrial-manual/access-online.

[97] L. A. Reddacliff, I. B. Marsh, S. A. Fell, S. L. Austin, and R. J. Whittington, "Isolation of Mycobacterium avium subspecies paratuberculosis from muscle and peripheral lymph nodes using acid-pepsin digest prior to BACTEC culture," Veterinary Microbiology, vol. 145, no. 1-2, pp. 122-128, 2010. 
[98] V. J. Timms, M. M. Gehringer, H. M. Mitchell, G. Daskalopoulos, and B. A. Neilan, "How accurately can we detect Mycobacterium avium subsp. paratuberculosis infection?" Journal of Microbiological Methods, vol. 85, no. 1, pp. 1-8, 2011.

[99] T. Balážová, J. Makovcová, O. Šedo, M. Slaný, M. Faldyna, and Z. Zdráhal, "The influence of culture conditions on the identification of Mycobacterium species by MALDI-TOF MS profiling," FEMS Microbiology Letters, vol. 353, no. 1, pp. 77-84, 2014.

[100] S. Hofmann-Thiel, L. Turaev, T. Alnour, L. Drath, M. Müllerova, and H. Hoffmann, "Multi-centre evaluation of the speed-oligo Mycobacteria assay for differentiation of Mycobacterium spp. in clinical isolates," BMC Infectious Diseases, vol. 11, article 353, 2011.

[101] M. Slany and I. Pavlik, "Molecular detection of nontuberculous mycobacteria: advantages and limits of a broad-range sequencing approach," Journal of Molecular Microbiology and Biotechnology, vol. 22, no. 4, pp. 268-276, 2012.

[102] K. Rantakokko-Jalava, S. Nikkari, J. Jalava et al., "Direct amplification of $r R N A$ genes in diagnosis of bacterial infections," Journal of Clinical Microbiology, vol. 38, no. 1, pp. 32-39, 2000.

[103] C. Guerrero, C. Bernasconi, D. Burki, T. Bodmer, and A. Telenti, "A novel insertion element from Mycobacterium avium, IS1245, is a specific target for analysis of strain relatedness," Journal of Clinical Microbiology, vol. 33, no. 2, pp. 304-307, 1995.

[104] M. Bartos, P. Hlozek, P. Svastova et al., "Identification of members of Mycobacterium avium species by Accu-Probes, serotyping, and single IS900, IS901, IS1245 and IS901-flanking region PCR with internal standards," Journal of Microbiological Methods, vol. 64, no. 3, pp. 333-345, 2006.

[105] I. Slana, P. Kralik, A. Kralova, and I. Pavlik, "On-farm spread of Mycobacterium avium subsp. paratuberculosis in raw milk studied by IS900 and F57 competitive real time quantitative PCR and culture examination," International Journal of Food Microbiology, vol. 128, no. 2, pp. 250-257, 2008.

[106] L. Dvorska, M. Bartos, O. Ostadal, J. Kaustova, L. Matlova, and I. Pavlik, "IS1311 and IS1245 restriction fragment length polymorphism analyses, serotypes, and drug susceptibilities of Mycobacterium avium complex isolates obtained from a human immunodeficiency virus-negative patient," Journal of Clinical Microbiology, vol. 40, no. 10, pp. 3712-3719, 2002.

[107] M. Moravkova, J. Lamka, M. Slany, and I. Pavlik, "Genetic IS901 RFLP diversity among Mycobacterium avium subsp. avium isolates from four pheasant flocks," Journal of Veterinary Science, vol. 14, no. 1, pp. 99-102, 2013.

[108] V. C. Thibault, M. Grayon, M. L. Boschiroli et al., "New variable-number tandem-repeat markers for typing Mycobacterium avium subsp. paratuberculosis and $M$. avium strains: comparison with IS900 and IS1245 restriction fragment length polymorphism typing," Journal of Clinical Microbiology, vol. 45, no. 8, pp. 2404-2410, 2007.

[109] J. W. Wynne, T. Seemann, D. M. Bulach, S. A. Coutts, A. M. Talaat, and W. P. Michalski, "Resequencing the Mycobacterium avium subsp. paratuberculosis K10 genome: improved annotation and revised genome sequence," Journal of Bacteriology, vol. 192, no. 23, pp. 6319-6320, 2010.

[110] J. L. Gardy, J. C. Johnston, S. J. Ho Sui et al., "Whole-genome sequencing and social-network analysis of a tuberculosis outbreak," The New England Journal of Medicine, vol. 364, no. 8, pp. 730-739, 2011.

[111] M. Kato-Maeda, J. Z. Metcalfe, and L. Flores, "Genotyping of Mycobacterium tuberculosis: application in epidemiologic studies," Journal of Future Microbiology, vol. 6, no. 2, pp. 203216, 2011. 


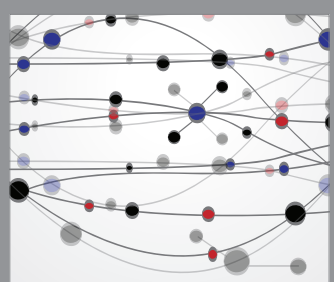

The Scientific World Journal
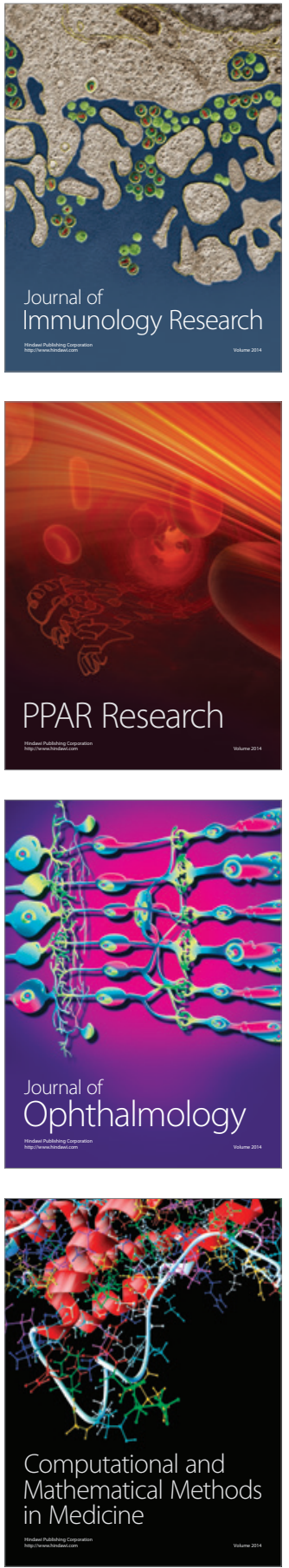

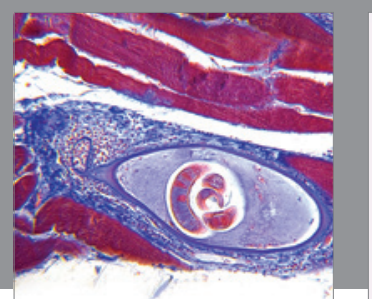

Gastroenterology Research and Practice

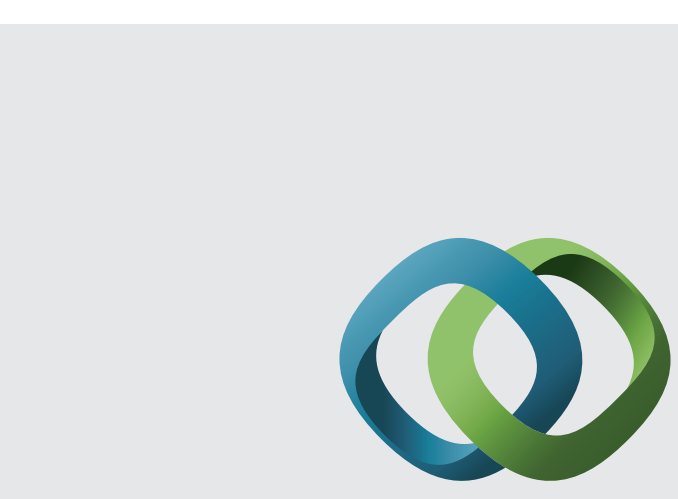

\section{Hindawi}

Submit your manuscripts at

http://www.hindawi.com
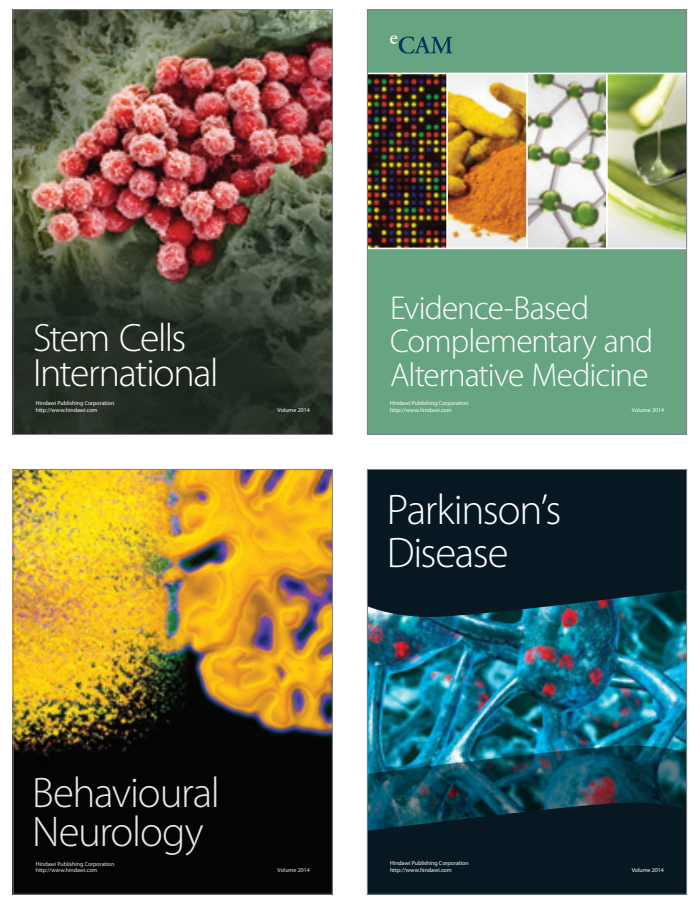
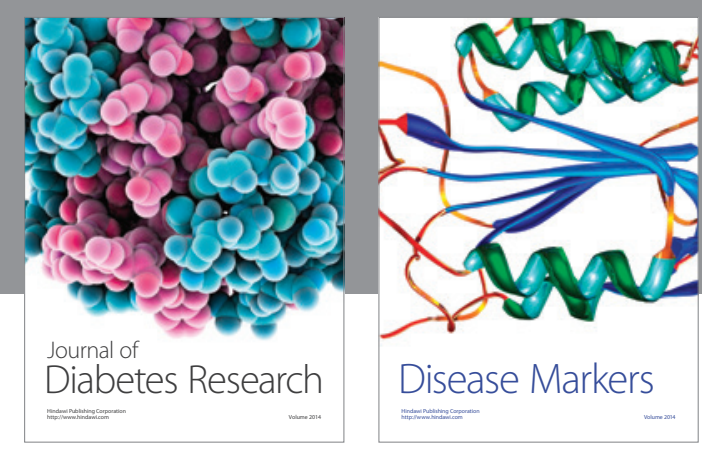

Disease Markers
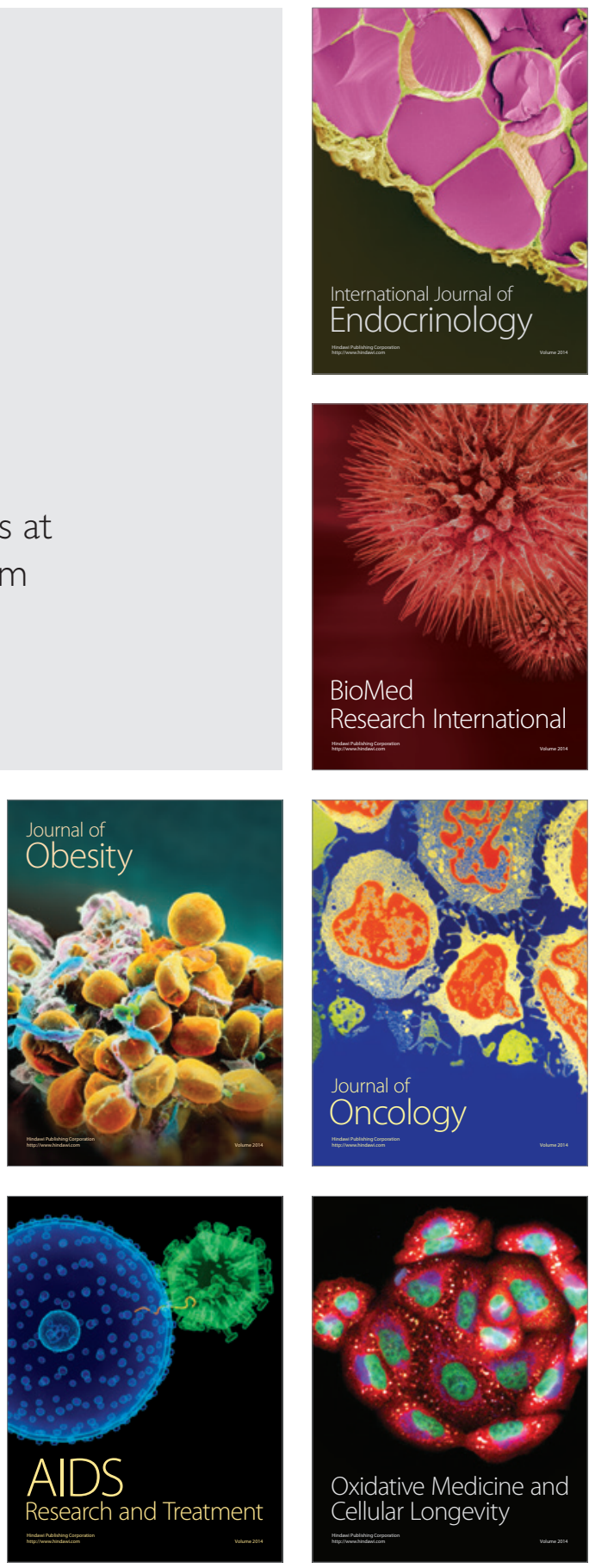